\title{
Da importância da diversidade linguística na conformação do conceito saussuriano de língua
}

\author{
Janaína Nazzari Gomes ${ }^{1}$
}

\section{Resumo}

O presente estudo parte das reflexões de Ferdinand de Saussure acerca do fenômeno da diversidade linguística com vistas a compreender como tais reflexões contribuiram para a conformação do construto teórico saussuriano sobre a lingua. De fato, apesar de ter sido realocado para a quarta parte do Curso de Linguistica Geral (1916), a análise do fenômeno (as linguas) fora a primeira parte do terceiro e último curso que o genebrino proferiu em Genebra entre 1910 e 1911. Percurso semelhante ao do terceiro curso é igualmente encontrado nas três conferências de Genebra, proferidas em 1891, ou seja, duas décadas antes do terceiro curso de linguística geral. A permanência da análise do fenômeno para a posterior elaboração do construto teórico fornece-nos pistas acerca de sua importância para o conceito saussuriano de lingua.

Palavras-chave: Diversidade linguística. Conceito de lingua. Saussure

${ }^{1}$ Doutoranda em Ciências da Linguagem pela Universidade Federal do Rio Grande do Sul e bolsista do CNPq. Tem mestrado na mesma área e é graduada em Letras - Português/Francês. 


\section{Introdução}

O presente estudo é fruto de um entrecruzamento de leituras do Curso de Linguística Geral (doravante Curso) e dos cadernos de Émile Constantin (CONSTANTIN, 2005), aluno do segundo e do terceiro cursos de linguística geral ministrados por Ferdinand de Saussure, em Genebra, na primeira década do século XX. Dessa empresa, pudemos perceber concretamente aquilo que De Mauro (1967) havia salientado já em sua edição crítica: os editores do Curso, Charles Bally e Albert Sechehaye, haviam invertido a ordem dos ensinamentos de Saussure, quando este ministrara a terceira edição do curso de linguística geral, entre 1910 e 1911. Ou seja: o mestre genebrino iniciara suas aulas pela análise da diversidade linguística (as linguas), para, somente então, adentrar nas reflexões sobre a lingua. Assim, apesar de as linguas serem o fenômeno a partir do qual Saussure introduziu a segunda parte do terceiro curso (a língua), tal temática fora relegada ao final do Curso (quarta parte) e intitulada "Linguística geográfica", expressão que não encontramos nem nas notas preparatórias ao terceiro curso (SAUSSURE, 2002) nem nos cadernos de Constantin (2005).

Além disso, duas décadas antes de seu derradeiro curso, em 1891, Saussure proferira três conferências, também em Genebra, nas quais partira igualmente da diversidade linguística para explicitar as propriedades da lingua. Em ambos os percursos, o mestre genebrino elencara a mutabilidade e a continuidade linguísticas como princípios fundamentais de qualquer sistema e operara com o conceito de estado de lingua para fazê-lo. Além disso, tendo como base esses mesmos operadores teóricos, Saussure rebatera, de um lado, as noções de língua e de dialeto que associavam determinados sistemas linguísticos a determinados territórios e, de outro, a noção de vida da língua, deveras corrente em sua época.

Percebemos, portanto, que, em um espaço de vinte anos, o estudo da diversidade linguística parece ter sido o fenômeno linguístico a partir do qual Saussure se baseara para conformar o que hoje é conhecido como a teoria saussuriana: o conceito de língua como um sistema de signos, que são formados por significante e significado; estes, por sua vez, são associados arbitrariamente, e sua existência não é senão opositiva, do que decorre a noção de valor.

\footnotetext{
${ }^{2}$ Neste artigo, utilizaremos a edição do Cours de Linguistique Générale estabelecida por Tullio de Mauro (1967).
} 
Neste estudo, procuraremos, então, colocar em relação o preâmbulo da reflexão saussuriana - o estudo da diversidade linguística - e o elixir da referida teoria - o construto sobre a língua - com vistas a tentar compreender como o primeiro pode ter influenciado o segundo. Trata-se, em última instância, de resgatar a importância que a observação do fenômeno da diversidade linguística teve para a conformação da teoria que fundou a linguística moderna.

\section{Breve estado da arte do pensamento saussuriano}

A obra legada por Ferdinand de Saussure não poderia se apresentar de maneira mais complexa aos leitores contemporâneos. A heterogeneidade de suas fontes, por si só, se revela um primeiro desafio para quem deseja tomar conhecimento do trabalho saussuriano. De fato, até hoje, podemos elencar somente duas fontes acadêmicas formalmente assinadas pelo linguista genebrino: o Mémoire sur le système primitif des voyelles dans les langues indo-européennes (defendido em 1879) e a tese intitulada De l'emploi du génitif absolut en sanskrit (defendida em 1881), ambas desenvolvidas em Leipzig (Alemanha) a partir do método histórico-comparatista. Afora sua dissertação e sua tese, foram encontrados, em diferentes momentos do século $\mathrm{XX}$, inúmeros escritos autográficos contendo notas preparatórias para aulas, reflexões acerca da dupla essência da linguagem e sobre aspectos fônicos da língua, e estudos sobre anagramas greco-latinos, entre outros. Voltaremos a eles na sequência.

Apesar da existência de tais manuscritos, a obra saussuriana fora primeira e mundialmente veiculada pelas mãos de Charles Bally e Albert Sechehaye em 1916, com a publicação do Curso, elaborado a partir da análise de alguns manuscritos do linguista e, sobretudo, de cadernos dos alunos que participaram dos cursos ministrados em Genebra entre 1907 e 1911. A heterogeneidade autoral do Curso suscitou, segundo Mejía Quijano (2005), a curiosidade de outros linguistas, que acabaram por elaborar estudos sobre os manuscritos que serviram de fonte para a publicação da obra fundadora da linguística moderna. Nesse sentido, é mister citar a tese de Robert Godel, defendida em 1957, intitulada Les sources manuscrites du Cours de Linguistique Générale; a edição crítica do Curso elaborada por Rudolf Engler e finalizada em 1968, que contém cadernos de vários alunos (SAUSSURE, 1989); também, a edição crítica de Tullio de Mauro (SAUSSURE, 1967), que 
apresenta preciosas notas sobre as fontes manuscritas; e publicações de Eisuke Komatsu, a partir de 1993.

Além das publicações concernentes às fontes do Curso, fez-se, igualmente, ao longo do século XX, a descoberta de outros manuscritos saussurianos e a publicação de cadernos de alunos de Saussure. Sobre os primeiros, podemos citar o manuscrito de Harvard, intitulado Phonétique e publicado em 1995 sob a cura de Maria Pia Marchese; o manuscrito sobre as soantes, publicado em 2002, também sob a cura de Marchese; os cadernos sobre os anagramas, analisados por Jean Starobinski em 1971 e por Testenoire em 2013; o manuscrito sobre a dupla essência da linguagem, publicado em 2002 por Simon Bouquet e Rudolf Engler e, em 2011, por René Amacker. Além disso, uma vasta gama de intérpretes da teoria saussuriana emergiu após a segunda metade do século XX e continua a emergir no século XXI, tanto no que diz respeito a pesquisas retrospectivas (filológicas) quanto a pesquisas prospectivas, que tomam as reflexões saussurianas como ponto de partida para reflexões linguísticas gerais ${ }^{3}$.

Com o exposto, é possível perceber a heterogeneidade das fontes do pensamento saussuriano. Além dos trabalhos desenvolvidos na Alemanha e do Curso, o que resta à grande maioria de seus leitores são, de um lado, edições dos manuscritos e dos cadernos dos alunos e, de outro, as interpretações da teoria. No presente artigo, nos basearemos, sobretudo, nos primeiros, como veremos na seção seguinte.

\section{O corpus escolhido}

Neste estudo, nosso ponto de partida serão as considerações saussurianas acerca da diversidade linguística. Analisaremos, primeiramente, como o raciocínio saussuriano é construído nas conferências proferidas em Genebra em 1891, presentes nos Escritos de linguística geral (SAUSSURE, 2002) ${ }^{4}$; e nos cadernos de Émile Constantin (2005), publicados no Cahiers Ferdinand de Saussure. Em um segundo momento, nos dedicaremos a associar

\footnotetext{
${ }^{3}$ Convém citar, no âmbito mundial, os trabalhos de Bouquet (2004), Arrivé (2010), Normand (2009), Gadet (1987), Depecker (2012), Coursil (2000), Parret (2014), D’Ottavi (2010); e, no espectro brasileiro, as reflexões de Milano (2016, 2017), Flores (2017), Silveira (2007), Pereira Castro (2010) e Stawinski (2016).

${ }^{4}$ Embora a versão de Amacker (SAUSSURE, 2011) apresente uma releitura, do ponto de vista filológico, muito mais completa do que a edição de Bouquet e Engler (SAUSSURE, 2002), utilizaremos esta última por conter os antigos documentos - dentre os quais, as três conferências proferidas em Genebra em 1891, um dos corpora deste estudo.
} 
os achados decorrentes das primeiras análises a conceitos internos à teoria sobre a língua, presente na segunda parte do terceiro curso de linguística geral (CONSTANTIN, 2005). Secundariamente, nos valeremos, também, das considerações de Mejía Quijano (2005), das notas de De Mauro (1967) e das notas preparatórias para os três cursos de linguística geral (SAUSSURE, 2002). Desses corpora, somente os Escritos de linguística geral (SAUSSURE, 2002) estão traduzidos para o português, então, para todas as citações dessa obra, utilizaremos a versão já traduzida. Para os cadernos de Constantin (2005) e as considerações de Mejía Quijano (2005) e de De Mauro (1967), que estão em francês, utilizaremos sua versão original. Pedimos, pois, a compreensão do leitor para a ausência de tradução, que se justifica pelo reduzido espaço de um artigo.

Por nossa parte, escolhemos trabalhar com as fontes supracitadas por apresentarem, em um espaço de duas décadas, reflexões deveras coesas entre si. Com efeito, o fato de a diversidade linguística se manter durante tanto tempo no espírito saussuriano oferece-nos pistas sobre a importância de tal fenômeno para a conformação da teoria sobre o sistema linguístico.

\section{Das línguas à língua: um percurso indispensável para todo linguista}

Relegada à quarta parte do Curso de Linguística Geral sob o nome de "Linguística Geográfica”, a reflexão saussuriana acerca da diversidade linguística fora, porém, como já pontuamos, a primeira temática abordada no terceiro curso de Genebra. Mais do que um mero preâmbulo, o estudo do fenômeno se impõe, segundo Saussure, como o ponto de partida para todo linguista que vise à identificação das leis fundamentais que regem qualquer sistema:

[...] le langage de l'ensemble de l'humanité se manifeste par une diversité de langues infinie: la langue est le produit d'une société, mais les différentes sociétés n'ont pas la même langue. D’où vient cette diversité? Tantôt c'est une diversité relative, tantôt c'est une diversité absolue, mais enfin nous avons trouvé l'objet concret dans ce produit que l'on peut supposer déposé dans le cerveau de chacun. Mais ce produit, suivant qu'on se place à tel endroit du globe, est différent; la <chose> donnée, ce n'est pas seulement la langue mais les langues. Et le linguiste est dans l'impossibilité d'étudier autre chose au début que la diversité des langues. Il doit étudier d'abord les langues, le plus possible de langues; il doit étendre son horizon autant qu'il le peut. C'est ainsi que nous procéderons. Par l'étude, l'observation de ces langues, il pourra tirer des traits généraux, il retiendra tout ce qui lui parait essentiel et universel, 
pour laisser de côté le particulier et l'accidentel. Il aura devant lui un ensemble d'abstractions qui sera la langue. C'est ce qu'on peut résumer dans cette seconde division: la langue. Dans la langue, nous résumons ce que nous pouvons observer dans les différentes langues (CONSTANTIN, 2005, p. 89).

Como podemos ler no excerto acima, a diversidade linguística constitui o fenômeno a partir do qual o linguista tece hipóteses acerca dos mecanismos internos à língua, isto é, ao sistema. Assim, como veremos na sequência, do estudo das línguas, Saussure pôde concluir sobre as variações do sistema no tempo e no espaço, se perguntar sobre as causas da diversidade linguística, perceber a semelhança entre certas línguas e a profunda diferença entre outras e questionar a noção de língua e de dialetos.

Como já assinalamos, o mesmo raciocínio está presente nas conferências de Genebra em 1891, ou seja, duas décadas antes do derradeiro curso de linguística geral ministrado por Saussure. A permanência de um mesmo raciocínio que vai das línguas à lingua, em tão largo espaço de tempo, nos leva a perguntar sobre a sua importância para o construto teórico saussuriano. Assim, passaremos em escrutínio ambas as fontes a fim de compreender como a relação entre a diversidade linguística e o conceito de língua é construída.

\section{As conferências de Genebra}

Nas três conferências de Genebra em 1891, Saussure parte da constatação da variação das línguas no tempo e no espaço para, de um lado, combater a noção de vida da língua e, de outro, desenvolver os dois princípios fundamentais que regem qualquer sistema linguístico: a continuidade e a mutabilidade linguísticas, ambas ocasionadas pela dimensão temporal. Para o presente estudo, interessa-nos, sobretudo, o segundo.

Assim, o mestre verifica, primeiramente, o princípio da continuidade da língua no tempo, sua unicidade:

Vale a pena nos deter por um instante diante do princípio, elementar e essencial, da continuidade ou da não interrupsão forçada, que é a primeira característica ou a primeira lei de transmissão do falar humano, sejam quais forem, à volta da língua, as revoluções e os abalos de qualquer tipo 
que podem mudar todas as condições [ $]^{5}$. [...] cada indivíduo emprega, no dia seguinte, o mesmo idioma que falava no anterior e é isso que sempre se observa (SAUSSURE, 2002, p. 133, grifos do autor).

Em seguida, ao perceber que as línguas permanecem ao mesmo tempo em que mudam, postula, ao lado da continuidade, o princípio da mutabilidade linguística:

Se, como acabamos de colocar, nenhuma interrupção, [...] é imaginável na tradição da língua, se é verdade que a língua do dia seguinte sempre existiu na véspera, da mesma forma, pergunta-se como é que não falamos hoje o latim que falava Júlio César, como é que Júlio César não falava o indo-europeu de seus primeiros ancestrais. [...]

Chegamos, assim, ao segundo princípio, de valor universal como o primeiro, cujo conhecimento pode revelar o que é a história das línguas: é o ponto de vista do movimento da lingua no tempo, mas de um movimento que, de modo algum, já que tudo está ali, chega a entrar em conflito com o primeiro princípio, da unidade da língua no tempo. Há transformação, ainda e sempre transformação, mas não há, em parte alguma, reprodução ou produção de um ser linguístico novo, com existência distinta do que o precedeu e do que se seguirá a ele (SAUSSURE, 2002, p. 133, grifos do autor).

Ao postular, pois, "o princípio da transformação incessante das línguas como absoluto" (SAUSSURE, 2002, p. 138), Saussure passa a se perguntar sobre os mecanismos internos ao sistema que permitem ou até mesmo incitam tal transformação. Enumera, então, dois grandes fatores de renovação linguística: a mudança fonética e a transformação analógica, que deveriam ser, inclusive, "a ocupação quase exclusiva do linguista" (SAUSSURE, 2002, p. 139).

Sobre o mecanismo analógico, Saussure nos diz:

Não há melhor maneira de perceber o que é isso do que escutar falar, [...], uma criança de três a quatro anos. Sua linguagem é um verdadeiro tecido de formações analógicas, [...], que oferecem [...] o princípio que não cessa de agir na história das línguas. Venirai. Como je venira? Para isso, é preciso que, [...], a criança conheça venir e que associe, em seu espírito, a ideia contida em venir com a que deseja exprimir; mas isso não basta; é preciso, [...] que ela tenha ouvido dizer punir e je te punirai ou choisir [je choisirai]. Então, acontece o fenômeno punir: punirai $=$ venir: venirai. Nada de mais consequente, nada de mais lógico e de mais certo do que o raciocínio que conduz a venirai (SAUSSURE, 2002, p. 140, grifos do autor).

E, então, interpreta-o a partir do ponto de vista que está a desenvolver, a linguística estática:

\footnotetext{
${ }^{5}$ Não é raro encontrar, nos manuscritos saussurianos, diversos colchetes vazios, que, em sua maioria, indicam dificuldade de compreensão de seu conteúdo por parte dos editores.
} 
[...] em certo sentido, isso não é uma transformação, é uma criação; mas, em última análise, não passa de uma transformação, já que todos os elementos de venirai estão contidos nas formas existentes, fornecidas pela memória: punirai, punir ou, então, se assim se desejar, o sufixo -ir, o sufixo -irai e sua relação de significação. Sem a presença desses elementos, venirai é simplesmente impossível. Não haverá jamais criação ex nibilo, mas cada inovação será uma nova aplicação de elementos fornecidos pelo estado anterior da linguagem. É assim que a renovação analógica que, em certo sentido, é muito destrutiva, se limita a continuar a cadeia de elementos transmitidos desde a origem das línguas, sem jamais conseguir rompê-la (SAUSSURE, 2002, p. 140, grifos do autor).

Nesse ponto, embora o mestre esteja tratando do fenômeno da diversidade linguística (ou seja, das línguas), vemos que ele já lança mão de reflexões sobre o sistema (a língua) para explicar o mecanismo analógico. Tal é o caso da noção de estado de língua (veiculada pela expressão estado anterior da linguagem), que está, por sua vez, diretamente associada à dimensão temporal que interpela a continuidade e a mutabilidade linguísticas. Além disso, Saussure vai além: utiliza as noções de formas no espírito e de ideias representadas, que virão a ser, duas décadas depois, os conceitos de significante e de significado:

Observemos, também, em seguida, por que se dá o nome de operação de analogia, de fatos de analogia, a todas essas operações psicológicas. [...] ele [o termo] se revelou aplicável, já que o resultado dessas operações tende a restabelecer uma analogia ou uma simetria entre as formas; assim, viendrai não é simétrico a punirai. É sobre uma analogia que se efetua o raciocínio que está na base do fenômeno. Mais geralmente, esse fenômeno representa uma associação de formas no espirito, ditada pela associação de ideias representadas (SAUSSURE, 2002, p. 140, grifos do autor).

Após tecer explicações sobre as mudanças analógicas, Saussure trata muito brevemente das mudanças fonéticas, afirmando que "por razões que não seria possível expor [...], ela [a mudança fonética] escapa à nossa atenção e à nossa consciência" (SAUSSURE, 2002, p. 142), muito embora esteja presente em todas as línguas.

No momento final das três exposições feitas em Genebra, Saussure se centra sobre as noções de língua e de dialeto. Trata-se, ainda uma vez, de desdobramentos das reflexões acerca da diversidade linguística interpelada pelo tempo. Nesse ponto, porém, Saussure acrescenta a seu raciocínio um novo elemento, qual seja, a dimensão espacial:

[...] se uma mesma língua se espalha em um momento determinado sobre uma certa extensão de território, o resultado da mudança inevitável, ao fim de cem ou duzentos anos, não é o mesmo nos diferentes pontos desse território, tenha ele um diâmetro de quinhentas ou seiscentas léguas ou de cinco ou seis léguas. Os fenômenos ocorridos no instante são sempre absolutamente precisos e definíveis, por exemplo, a mudança de $s$ para $h$, mas não são os mesmos nas diferentes 
partes da área geográfica considerada; - e, por conseguinte, a língua não é mais idêntica nas diferentes regiões que atravessa.

Quando se combina esse dado geográfico com o dado cronológico, percebe-se que [nós] não nos encontramos, quase nunca, em linguística, diante de um primeiro termo A refletido, alguns séculos depois, em um termo $\mathrm{B}$; mas diante de um primeiro termo $\mathrm{A}$ que repercute, alguns séculos depois, em B' B" B"' B"'” (SAUSSURE, 2002, p. 145).

É, pois, ao confrontar a multiplicidade linguística presente no globo à aparente especificidade dialetal de determinado território - à luz, evidentemente, dos princípios de mutabilidade e continuidade linguística - que a própria questão da existência de línguas e dialetos é colocada em xeque:

a área geográfica dos fenômenos pode perfeitamente ser traçada no mapa, mas que tentar distinguir unidades dialetais é absolutamente quimérico e inútil. [...] Assim como não há dialetos delimitados, não há línguas delimitadas, nas condições normais.

Assim, a língua, que não é, como vimos, uma noção definida no tempo, não é, também, uma noção definida [no espaço] (SAUSSURE, 2002, p. 148-149).

Nesse sentido, é preciso notar: segundo as análises do mestre genebrino, a situação geográfica tem efeitos reduzidos sobre a língua, já que esta tem mecanismos internos que tendem à mudança, o que, por sua vez, se passa principalmente no eixo temporal. A inclusão do fator geográfico na reflexão saussuriana em questão visa sobretudo à explicitação da arbitrariedade com que se atribui a determinado território um determinado dialeto ou uma determinada língua, já que a mutabilidade é a regra do sistema. Saussure nos oferece, como habitualmente, uma metáfora, que, embora longa, é deveras elucidativa:

Imaginemos, numa cidade, uma rua muito longa: pode-se discutir, nos conselhos municipais, se vai lhe ser dado, em todo o seu comprimento, um único nome; por exemplo, Bulevar Nacional; ou se essa rua será dividida em duas partes, Bulevar do Tempo e Bulevar da Escola, ou três, bulevar de $\mathrm{X}$, de $\mathrm{Y}$ e de $\mathrm{Z}$ ou, enfim, em dez, quinze, frações, com nomes diferentes. A existência distinta de cada um desses trechos de rua é, naturalmente, uma coisa puramente nominal e fictícia, não cabe perguntar como o Bulevar Y se transforma em Bulevar X, nem se o Bulevar $\mathrm{Y}$ se transforma subitamente ou insensivelmente em Bulevar X, porque, para começar, não existe, em lugar algum, Bulevar Y ou Bulevar $\mathrm{X}$, exceto em nosso espírito. Do mesmo modo, não há em parte alguma, exceto em nosso espírito, um certo ser que seja o francês por oposição a um certo ser que seja o latim. [...] O essencial é compreender que podemos dar um nome só ao período de vinte e um séculos, denominando-o latim - ou então dois nomes, denominando-o latim e francês - ou então três nomes, denominando-o latim, românico e francês - ou então vinte e um nomes, denominando-o latim do século II antes de Cristo, do século I antes de Cristo, do século I depois de Cristo, dos séculos II, III, IV, VII, XII, XV, XIX depois de Cristo (SAUSSURE, 2002, p. 143-144, grifos do autor). 
E conclui, então, acerca da característica transitória de qualquer língua no espaço justamente porque se modifica no tempo:

[...] assim, nós negamos - [...] - não apenas, em segundo lugar, que uma língua possa subitamente nascer de uma outra, mas, em terceiro lugar, negamos que uma determinada língua nasça gradualmente de uma outra, pois não há nenhum instante em que a língua seja menos determinada nem mais determinada do que em outro; não existem, jamais, características permanentes, mas apenas transitórias e, além disso, delimitadas no tempo; existem apenas estados de lingua que são, perpetuamente, a transição entre o estado da véspera e o do dia seguinte; [...] (SAUSSURE, 2002, p. 144, grifos nossos).

Com esse último excerto, chegamos ao fim de nossa leitura das conferências proferidas em 1891 em Genebra. Convém, pois, perguntar-nos: como a análise da diversidade linguística parece ter contribuído para o construto teórico desenvolvido por Saussure? Ou ainda: se a língua tende à mudança e à continuidade, haveria aspectos internos a ela que apresentam tal propriedade? Empreenderemos a análise dos cadernos de Constantin (2005) antes de tentar fornecer respostas aos interrogantes que acabamos de colocar.

\section{O terceiro curso de linguística geral}

Após elaborar um apanhado cronológico sobre os diferentes estudos que vislumbraram a língua como um objeto passível de ser estudado, Saussure inicia o terceiro curso de linguística geral dedicando-se a estabelecer o objeto da linguística:

Sans séparer immédiatement les mots de langue et de langage, où trouvons-nous le phénomène concret, <complet>, intégral de la langue ou du langage? C'est-à-dire, où trouvons-nous l'objet devant lequel nous avons à nous placer avec tous ses caractères provisoirement contenus en lui et non analysés? (CONSTANTIN, 2005, p. 86).

Entreviu, assim, todos os pontos de vista a partir dos quais era possível observar traços da língua: o aparelho fonador; o aspecto acústico; a união da ideia e do produto do aparelho fonador; o indivíduo, que produz a união entre a ideia e o produto do aparelho fonador; a sociedade. Conclui que a língua se apresenta como uma reunião de coisas heterogêneas, mas que o que define o objeto é a associação entre a imagem acústica e uma ideia (CONSTANTIN, 2005, p. 87) e que o fenômeno a ser estudado pela linguística é a diversidade linguística: 
Les langues, c'est l'objet concret qui s'offre sur la surface du globe au linguiste; la langue, c'est le titre qu'on peut donner à ce que le linguiste aura su tirer < de général $>$ de l'ensemble de ses observations à travers le temps et à travers l'espace (CONSTANTIN, 2005, p. 93).

E, ainda:

Pour la linguistique, c'est bien le fait primordial que la diversité des langues. Il n'y a eu de linguistique que lorsque l'attention s'est portée sur cette diversité, qui a donné lieu de plus en plus à la comparaison et $[\ldots]$ à l'idée générale d’une linguistique (CONSTANTIN, 2005, p. 96).

Após a definição do fenômeno linguístico, a primeira parte do curso é marcada, pois, pela tentativa de compreensão das causas das diferenças entre as línguas. Saussure se pergunta:

Est-ce que c'est la différence de lieu (la distance dans l'espace)? Nous sommes portés à nous le figurer. Mais il suffit de réfléchir pour voir que ces différences ne sont amenées que par le temps. Changement implique temps écoulé. Les Saxons et Angles, au demain de leur débarquement, parlaient la même langue qu'ils parlaient la veille sur le continent (CONSTANTIN, 2005, p. 108).

Visto que a consideração do aspecto geográfico estava deveras presente nos debates linguísticos de sua época - tendendo a atribuir a um determinado território um determinado idioma ou dialeto -, Saussure a refuta, lembrando que a diferença entre idiomas se deve ao princípio da mutabilidade das línguas, que ocorre no tempo:

\footnotetext{
Lorsque nous sommes devant la différence géographique, nous ne saisissons que le produit d'un phénomène, son résultat, mais le phénomène est ailleurs. C'est comme si nous voulions juger d'un volume par une surface. Il faut avoir la profondeur, l'autre dimension. On voit que le phénomène n'est pas dans l'espace mais entièrement dans le temps. La différence géographique ne reçoit son complet schéma que quand on la projette dans le temps. La différence géographique est réductible directement à une différence de temps et doit y être réductible. Le phénomène doit être classé dans la colonne du temps. Même erreur que quand on dit qu'un fleuve monte, comme si l'eau montait du fond à la surface au lieu de couler (CONSTANTIN, 2005, p. 109).
}

Além disso, lembra Saussure, as modificações linguísticas não ocorrem da mesma forma ao longo de um território: "il faut ajouter comme deuxième point et fait certain que la forme de la langue ne sera pas modifiée de la même façon sur tout le territoire" (CONSTANTIN, 2005, p. 114). Nesse momento, o mestre genebrino parece tratar do que denominou, nas conferências, de fenômenos analógicos e fonéticos: 
Le changement sur chaque point se fera: $1^{\circ}$ ) Par innovations successives, précises, constituant autant de détails qu'on peut définir. On peut distinguer les éléments petits ou grands, éléments qui peuvent être très divers. Dans l'ordre morphologique: gëbames - gëbam(es),ou bien dans l'ordre phonétique s > z (CONSTANTIN, 2005, p. 115).

De fato, além de utilizar o termo "inovação", assim como fez nas conferências, Saussure forneceu exemplos de ordens diferentes, morfológicas e fonéticas, as mesmas das conferências. Ora, como vimos, os procedimentos analógicos são caracterizados justamente pela criação de novas formas linguísticas a partir de formas já existentes. Destarte, a falta da nomenclatura não parece prejudicar a caracterização do fenômeno.

Nesse ponto, compreendemos que todas as reflexões até aqui apresentadas nos levam para o debate já explicitado acerca da diferença entre as noções de língua e dialeto, ou seja, acerca dos diferentes graus, causas e fatores de diferenciação entre idiomas e, em última instância, sobre as particularidades que constituem um sistema linguístico. Vejamos como isso se desenrola.

Ao afirmar que “chaque région n'est que la transition dans tous les sens entre les régions environnantes. La grammaire d'un dialecte ne sera que celle d'un seul point" (CONSTANTIN, 2005, p. 122), Saussure retoma a noção de estado de lingua com que trabalhara nas conferências de Genebra. Por quê? Pois, ao observar que a língua se diferencia no espaço, percebe que não é, porém, o espaço que causa essas diferenciações, mas o tempo. Como cada sistema varia independentemente de sua situação geográfica, vai além: percebe que todo sistema linguístico é tão somente a transição entre sistemas e que, portanto, a nomenclatura língua/dialeto é inteiramente arbitrária. O mestre demonstra sua afirmação através do seguinte raciocínio:

Si l'on admettait une langue A (une) et une langue B qui soit également une, la présence d'une zone de transition paraitrait étonnante. Mais la langue $\mathrm{A}$ est une somme de dialectes se reliant à l'intérieur et la langue $\mathrm{B}$ est une somme de dialectes également. Tout est transition d'un bout à l'autre du territoire. $2^{\circ}$ ) Dans la formule que nous venons de donner, nous avons parlé de dialectes fermés, mais au fond il n'y a que des dialectes ouverts de tous les côtés, formés par somme des ondes $[\ldots]$ (CONSTANTIN, 2005, p. 125).

Falante de quase uma dezena de línguas e estudioso de tantas outras, Saussure parece, pois, ter percebido que a diferença entre as línguas oferece, no mínimo, duas interpretações: de um lado, aquela que associa uma língua ou um dialeto a um território, caso, por exemplo, dos atlas linguísticos de Gilliéron e de Wenker; de outro, aquele que 
observa que a diversidade linguística entre países e regiões é somente a face mais evidente de um fenômeno muito mais complexo e profundo, qual seja, de que, em qualquer ponto de qualquer território, os idiomas estão sempre sendo modificados pela ação do tempo (CONSTANTIN, 2005, p. 119). Tais modificações constituem o que Saussure chama de estado de língua e atestam tanto a abertura de um sistema linguístico quanto a sua continuidade. Ora, todos os sistemas linguísticos, sejam eles considerados dialetos ou línguas, apresentam características comuns com os demais sistemas linguísticos vizinhos. Assim:

De même, il n'y a pas de frontières entre deux langues parentes, s'il n'y a eu mouvement de peuple. Il n'y a que des transitions. Un dialecte quelconque est la transition entre deux autres, et cela dans tous les sens. C'est le même principe qui veut qu'il n'y ait pas de limites précises entre les langues, et qui subdivise langues en dialectes (CONSTANTIN, 2005, p. 124).

Chegando ao fim da análise dos cadernos de Constantin referentes à primeira parte do terceiro curso de linguística geral ministrado em Genebra, convém retomarmos uma questão central, porém, não muito evidente: o que constitui a dimensão geográfica no construto desenvolvido por Saussure? Qual é a relação entre a geografia e a diversidade linguística? Vimos, até aqui, que muitas das reflexões saussurianas - tanto nas conferências de Genebra quanto no terceiro curso - foram empreendidas para refutar noções correntes de sua época, como a de vida da língua e de língua e dialeto, que associavam um determinado estado de língua a um determinado lugar, dando ares de fixidez. Fora, portanto, no esforço de oferecer uma contraposição a essas perspectivas que Saussure entreviu o conceito de língua, enquanto sistema sempre tendendo à mudança e à continuidade.

Destarte, visto que nosso estudo busca resgatar a relevância da primeira parte do terceiro curso de linguística geral ministrado em Genebra (“As línguas”) para a conformação da teoria saussuriana, é mister, primeiramente, atentarmos para o fato de que o mestre jamais utilizou a expressão "linguística geográfica", que vem a ser, justamente, o título da quarta parte do Curso $^{6}$. Com efeito, o fenômeno que o linguista suíço observara não dizia respeito à relação entre língua e território, mas, ao contrário, ao fato de que, em

\footnotetext{
${ }^{6}$ Não encontramos explicações na edição crítica do Curso (DE MAURO, 1967) sobre as razões que levaram os editores do Curso a nomearem a quarta parte da obra de "Linguística geográfica". O que pudemos constatar, porém, é que Saussure não utiliza, em nenhuma das fontes que utilizamos, a expressão. Ao contrário, o mestre associa geografia à diversidade, como, por exemplo: "Diversidade geográfica da língua. [...]" (SAUSSURE, 2002, p. 265), "Formação da diversidade na continuidade geográfica" (SAUSSURE, 2002, p. 268).
} 
qualquer território, a língua mudava em função do tempo. Assim, é preciso retomar um excerto já analisado:

Lorsque nous sommes devant la différence géographique, nous ne saisissons que le produit d'un phénomène, son résultat, mais le phénomène est ailleurs. C'est comme si nous voulions juger d'un volume par une surface. Il faut avoir la profondeur, l'autre dimension. On voit que le phénomène n'est pas dans l'espace mais entièrement dans le temps. La différence géographique ne reçoit son complet schéma que quand on la projette dans le temps. La différence géographique est réductible directement à une différence de temps et doit y être réductible. Le phénomène doit être classé dans la colonne du temps. Même erreur que quand on dit qu'un fleuve monte, comme si l'eau montait du fond à la surface au lieu de couler (CONSTANTIN, 2005, p. 109).

Se adentrarmos um pouco mais no raciocínio saussuriano, vemos que, ao analisar a comparação entre fenômeno/produto do fenômeno e volume/superfície, é possível perceber uma nuance deveras importante entre as noções de espaço e de superficie, ou seja, entre o fenômeno e o produto do fenômeno: o espaço é o local em que há intersecção de diferentes ondas linguísticas, diferentes inovações no tempo, enquanto a superfície seria o fenômeno perceptível do produto dessas intersecções. Assim, no espaço, há, forçosamente, o fator tempo interagindo e o produto dessa ação, a superfície, donde a analogia saussuriana ao volume - três dimensões (espaço, tempo e superfície). É, porém, na superfície, única dimensão, que encontramos o produto do fenômeno, e é isso que é apresentado ao linguista e ao falante.

Saussure não elaborou, portanto, uma linguística geográfica aos moldes dos primeiros atlas linguísticos produzidos à sua época. Pelo contrário: dedicou-se a observar o fenômeno da diversidade linguística para dele deduzir as propriedades universais do sistema.

\section{Como a observação do fenômeno (as línguas) conduziu Saussure à teoria (a língua)}

Nos estudos sobre o fenômeno da diversidade das línguas, nos parece claro que o fator sempre presente nas conclusões saussurianas dizia respeito aos princípios de mutabilidade e de continuidade linguísticas. Decorrente desse primeiro achado, Saussure também afirmou a inexistência de línguas ou dialetos precisamente marcados no tempo e no espaço e estipulou que uma língua, seria, assim, nada mais que a transição entre outras línguas, ou seja, sempre um estado de língua. 
Com efeito, ao lermos continuamente os cadernos de Constantin referentes ao terceiro curso de linguística geral, vemos que a expressão estado de língua está constantemente operando na primeira parte do curso e que, em seguida, na segunda parte, Saussure passa a empregar também com o conceito de língua. É mister, pois, olharmos para essa concomitância terminológica.

De um lado, estado de língua é o que Saussure conclui da observação do fenômeno da diversidade linguística: uma língua é tão somente um sistema em constante modificação, donde a referência ao estado do sistema. Percebemos que o genebrino relaciona a expressão tanto aos efeitos do tempo - sobre o que já muito dissertamos no capítulo anterior quanto à noção de valor:

Comme dans le système sémitique (hébreu) il n'y a de distinction comme celle de futur et de passé, c'est-à-dire que ces idées $<$ de temps $>$ ne sont pas prédéterminées, mais n'existent qu'à l'état de valeur dans telle ou telle langue (CONSTANTIN, 2005, p. 287).

Ou ainda:

Dans le jeu d'échecs, une position donnée est comparable à un état de langue par ces trois choses: $1^{\circ}$ ) On sent que la valeur des pièces n'est déterminée que par leur position réciproque dans un système comme foot/feet singulier/pluriel. La valeur de chaque pièce dépend du système, et du système momentané. $3^{\circ}$ ) Qu'est-ce qui fait passer d'une position des pièces à l'autre, d'un système à l'autre, d'une synchronie à l'autre? C'est le déplacement d'une pièce, ce n'est pas un remue-ménage de toutes les pièces. Dans ce troisième fait, nous avons $<\mathrm{I})>$ le fait diachronique dans toute sa portée et dans tout ce qui le fait autre des faits synchroniques qu'il conditionne (CONSTANTIN, 2005, p. 267).

De outro, a constatação de que as línguas são, em verdade, estado de línguas parece ter sido imprescindível para Saussure empreender a cisão epistemológica entre linguística diacrônica e sincrônica (a que também chama de linguística estática) e, então, estabelecer o ponto de vista a partir do qual o linguista deverá olhar para o objeto:

il est juste de parler de deux perspectives fondamentales [...] comme exprimant ce qu'il y a dans un état ou ce qu'il y a dans une diachronie. Il est important de remarquer que la perspective statique concerne à la fois les sujets parlants et le linguiste; la perspective des objets statiques concerne soit la masse parlante, soit la grammaire. Pour la masse parlante, la perspective où se présentent les termes, c'est la réalité. [...] D'un autre côté, le linguiste doit, s'il veut comprendre un état de langue, se mettre lui-même dans cette perspective, et abandonner la perspective diachronique ou historique qui sera pour lui une gêne, un empêchement. La perspective verticale ou diachronique ne concerne que le linguiste (CONSTANTIN, 2005, p. 275). 
Disso é imprescindível concluir que, para propor o conceito de língua, Saussure teve como ponto de partida as línguas, que se mostraram, a um só tempo, mutáveis e contínuas. Além disso, viu que a mutabilidade não atrapalha o valor, já que o sistema se rearranja constantemente. Como vimos nas conferências de Genebra, Saussure também identificou um mecanismo em particular, responsável pela diversificação linguística: a analogia. Sobre isso, afirmou que uma língua é senão um emaranhado de formações analógicas. Eis, pois, uma primeira delimitação do conceito de língua a partir das reflexões saussurianas acerca da diversidade linguística. Precisamos aprofundar um pouco.

Ora, como Saussure afirmou, no início de seu curso, a respeito das línguas, é preciso compreender o que nelas há de universal e constante como fato linguístico. Assim, ao conceito de língua que acabamos de delimitar se junta igualmente a observação de que o que confere relativa unidade a um determinado sistema é seu caráter essencialmente social:

$<$ Dès lors $>$ La langue n'est pas libre parce que même a priori le temps donnera occasion aux forces sociales intéressant la langue d'exercer leurs effets, par la solidarité infinie avec les âges précédents. Mais ce ne serait là que la langue hors de sa réalité sociale, et irréelle (puisque ne comprenant qu'une partie de sa réalité). Pour qu'il y ait langue, il faut une masse parlante se servant de la langue. La langue pour nous résidait d'emblée dans l'âme collective (CONSTANTIN, 2005, p. 252).

É, portanto, com a observação de que toda língua é uma transição entre outras línguas, de que todos os sistemas linguísticos mudam e, ao mesmo tempo, permanecem, e de que a massa falante/alma coletiva é fator primordial para a existência de um sistema, que Saussure pôde construir o conceito de lingua.

Assim, nesse ponto, é preciso perceber que, no terceiro curso, Saussure sublinhou não somente a mutabilidade das línguas, ao tratar da diversidade linguística, mas também a mutabilidade do signo linguístico, afinal, como haveria mudança em um sistema se o próprio signo não fosse passível de mudança? E, ainda, como seria possível mudança sem que a associação entre significante e significado não fosse arbitrária e pudesse, portanto, realocar os valores dos próprios elementos do próprio sistema? Lemos:

Pourquoi disons-nous: homme, chien? Parce qu'on a dit avant nous homme, chien. La justification est dans le temps. Cela ne supprime pas l'arbitraire et ça le supprime. Cela n'empêche pas de voir lien entre question du temps et la question de l'arbitraire qui agissent l'une antinomiquement à l'autre. <En résumé> La non-liberté des signes composant la langue tient au côté historique, ou est une manifestation du facteur temps dans la langue, puisque cette non-liberté des signes repose 
sur la continuité du facteur temps dans la langue, <sur la continuité du signe à travers générations. Autre manifestation du facteur temps, ce fait, en apparence contraire au premier:> l'altération des signes quand ils ont à traverser un certain nombre de générations. $<$ C'est ainsi que $>$ le titre de notre chapitre parle à la fois de l'immutabilité et de la mutabilité $<$ (altérabilité $)>$ du signe. Les deux choses se touchent intimement en dernière analyse (CONSTANTIN, 2005, p. 241).

Destarte, um signo é passível de alterar-se somente porque ele continua. Como é possível observar essa continuação? Porque, segundo o mestre, novas associações entre significante e significado não ocorrem ex nibilo, mas pela realocação entre formas contidas no próprio sistema. Ora, a observação da diversidade linguística levou Saussure a perceber que as mudanças ocorriam a partir de formas já existentes nos sistemas linguísticos. Se isso não acontecesse, poderíamos pensar no nascimento e na morte de línguas, mas, assim como Saussure advoga nas conferências de Genebra (1891) e reafirma duas décadas depois, no terceiro curso, salvo casos excepcionais, os falantes se valem das formas da língua para criarem novas formas: "En toute altération, ce qui domine, c'est la persistance d'une bonne partie de ce qui existait. C'est une infidélité relative qui suppose qu'on s'appuie sur principe antérieur" (CONSTANTIN, 2005, p. 241).

Disso, repetimos: para propor o conceito de língua, Saussure teve como ponto de partida as línguas, que se mostraram, a um só tempo, mutáveis e contínuas, porque são faladas por uma massa social. Percebeu, também, que a mutabilidade não atrapalha o valor das unidades, já que o sistema se rearranja constantemente. Além disso, como lemos nas conferências de Genebra, Saussure também identificou um mecanismo em particular, responsável pela diversificação linguística vista a partir de sua sincronia: a analogia. Sobre isso, afirmou que uma língua é senão, um emaranhado de formações analógicas. Eis, pois, nossa delimitação que fazemos do conceito de lingua.

A partir do exposto, pois, nos parece possível pensar que o conceito de língua saussuriano está profundamente arraigado nas reflexões que o mestre empreendeu acerca da diversidade linguística, o que faz dessa temática deveras pertinente para a compreensão integral do construto teórico saussuriano. Destarte, qualquer sistema linguístico é um sistema que tende, sempre, à mudança e à continuidade no tempo, justamente porque a associação entre as partes do signo é arbitrária. A relação entre significante e significado é passível, portanto, de ser constantemente realocada, já que se trata de uma característica inerente à língua. Com isso, percebemos que qualquer sistema linguístico não é fixo, mas estável, e que qualquer modificação se vale das formas já existentes no sistema para 
ocorrer. Ora, o que de mais evidente tem a diversidade linguística a dizer sobre a língua senão o fato de que cada sistema linguístico associa diferentemente formas significantes e formas significadas? É, pois, na diversificação da associação entre ideias e conceitos ${ }^{7}$, feita por uma determinada massa falante, que reside a diversidade linguística.

\section{Referências}

ARRIVÉ, Michel. Em busca de Ferdinand de Saussure. São Paulo: Parábola Editorial, 2010.

BOUQUET, Simon. Introdução à leitura de Saussure. São Paulo: Cultrix, 2004.

CONSTANTIN, Emile. Linguistique générale, Cours de M. le Professeur de Saussure, 1910-1911. Cahiers Ferdinand de Saussure - Revue suisse de linguistique générale, Genebra, v. 58, p. 83-289, 2005. Disponível em:

$<$ http://www.cerclefdsaussure.org/download/cfs_pdf/Volume_58_2006.pdf>. Acesso em: 10 abr. 2018.

COURSIL, Jacques. La fonction muette du langage: essai de linguistique générale.

Guadeloupe: Ibis Rouge Éditions, 2000.

DE MAURO, Tullio. Notes biographiques et critiques sur F. de Saussure. In: SAUSSURE, Ferdinand de. Cours de Linguistique Générale. Paris: Payot, 1967, p. 319-495.

DEPECKER, Louis. Compreender Saussure a partir dos manuscritos. Porto Alegre: Vozes, 2012.

D'OT'TAVI, Giuseppe. Ferdinand de Saussure e monsieur B. Rivista de critica, storia letteraria, filologia e linguística, Roma, v. 1, ano 7, p. 71-91, jan./jun. 2010.

FLORES, Valdir do Nascimento. Saussure e Benveniste no Brasil. São Paulo: Parábola Editorial, 2017.

GADET, Françoise. Saussure: une science de la langue. Paris: PUF, 1987.

MEJÍA QUIJANO, Claudia. Rudolph Engler - L'ouvrage d'un philologue artiste. Cahiers Ferdinand de Saussure - Revue suisse de linguistique générale, Genebra, v. 58, p. 5-19, 2005. Disponível em:

<http://www.cerclefdsaussure.org/download/cfs_pdf/Volume_58_2006.pdf>.Acesso em: 10 abr. 2018.

\footnotetext{
7 Neste trabalho, não adentraremos na discussão entre as duas faces do signo, porém reconhecemos sua complexidade, já que, de um lado, podemos observar importante oscilação terminológica na obra saussuriana, e, de outro, a face significante pode ser tratada unicamente como forma abstrata ou, ainda, como tendo uma dupla face, uma abstrata e outra material.
} 
MILANO, Luiza. O que cabe em um signo linguístico: o caso do fonema. Eutomia, Recife, v. 1, no 17, p. 67-78, 2016.

Le statut du phonique dans le CLG. Cahiers Ferdinand de Saussure - Revue suisse de linguistique générale, Genebra, v. 70, p. 85-100, 2017.

NORMAND, Claudine. Saussure. São Paulo: Estação Liberdade, 2009.

PARRET, Herman. Le son et l'oreille: six essais sur les manuscrits saussuriens de Harvard. Limoges: Lambert-Lucas, 2014.

PEREIRA CASTRO, Maria Fausta. Saussure e o necessário esquecimento da fala infantil: uma leitura para a aquisição da linguagem. Cadernos de Estudos Linguísticos, Campinas, v. 52, no 1, p. 91-102, 2010.

SAUSSURE, Ferdinand de. Cours de linguistique générale. Edição crítica preparada por Tullio de Mauro. Paris: Payot, 1967.

Cours de linguistique générale. Edição crítica preparada por Rudolf Engler. Wiesbaden: Otto Harrassowitz, 1989.

Escritos de Linguística Geral. Organizados e editados por Simon Bouquet e Rudolf Engler. São Paulo: Cultrix, 2002.

Science du langage: de la double essence du langage et autres documents du Ms. BGE Arch. De Saussure 372. Edição crítica preparada por René Amacker. Genebra: Librairie Droz, 2011.

SILVEIRA, Eliane. As marcas do movimento de Saussure na fundação da linguística. São Paulo: Mercado das Letras/Fapesp, 2007.

STAWINSKI, Aline. $\mathbf{O}$ aspecto fônico da língua: uma reflexão sobre o lugar do ouvinte na proposta saussuriana. Dissertação (Mestrado em Letras). Porto Alegre: Universidade Federal do Rio Grande do Sul, 2016. Disponível em:

<http://hdl.handle.net/10183/140177>. Acesso em: 20 mar. 2018. 


\section{Abstract}

This study is based on the reflections by Ferdinand de Saussure on the phenomenon of linguistic diversity, aiming to understand how they contributed to the conformation of the Saussurian theoretical construct on langue. In fact, even though it was reallocated to the fourth part of the Course in General Linguistics (1916), the analysis of the phenomenon (languages) had been the first part of the third and last course the Genevan gave in Geneva between 1910 and 1911. A similar path to the third course is equally found in the three Geneva conferences, given in 1891, two decades before the third course in general linguistics. The permanence of the analysis of the phenomenon for the later development of the theoretical construct provides us clues regarding its importance for the Saussurian concept of langue.

Keywords: Linguistic diversity. Langue. Saussure

Recebido em: 30/04/2018.

Aceito em: 10/07/2018. 